WWW.IAEE.ORG

The following article is a preprint of a scientific paper that has completed the peer-review process and been accepted for publication within The Energy Journal.

While the International Association for Energy Economics (IAEE) makes every effort to ensure the veracity of the material and the accuracy of the data therein, IAEE is not responsible for the citing of this content until the article is actually printed in a final version of The Energy Journal. For example, preprinted articles are often moved from issue to issue affecting page numbers, and actual volume and issue numbers. Care should be given when citing Energy Journal preprint articles. 


\title{
Switching Energy Suppliers: It's Not All About the Money
}

\author{
David Deller, ${ }^{a}$ Monica Giulietti, ${ }^{b}$ Graham Loomes, ${ }^{c}$ Catherine Waddams Price, ${ }^{d}$ \\ Anna Moniche, ${ }^{e}$ and Joo Young Jeon ${ }^{f}$
}

\begin{abstract}
Many consumers do not take advantage of lower energy prices available in liberalized retail markets. We provide evidence to explain why consumers may leave substantial amounts of "money on the table" in this way. We observe real decisions made by over 7,000 consumers in a collective switching auction, supplemented by their responses to a survey. We identify factors which may inhibit switching and show that expectations of high switching rates in an unregulated market may be unrealistic. Our findings have important implications for the design and regulation of energy markets, including imposition of price caps on "default" retail tariffs in 2019 in the UK and parts of Australia.
\end{abstract}

Keywords: Retail energy market, Switching suppliers, Probit models, Behavioral consumers

https://doi.org/10.5547/01956574.42.3.ddel

\section{INTRODUCTION}

The UK government has introduced price caps on "default" retail energy prices, ${ }^{1}$ sixteen years after removing price regulation from the market. Its primary declared objective is fairness to consumers who "leave money on the table". ${ }^{2}$ This price cap policy follows a decade of intervention from governments and regulators to address consumer "inertia" which has yielded disappointing results, as many consumers seem to remain "disengaged". There are particular concerns for households in hardship who pay more than necessary for a commodity that absorbs a significant proportion of their income. The regulator has seen low switching rates as problematic since its Energy Supply Probe (Ofgem, 2008), and the Competition and Markets Authority (2016) found an Adverse Effect on Competition from weak customer response. Such disengagement does not sit easily with

1. See "Draft Domestic Gas and Electricity (Tariff Cap) Bill', Department for Business, Energy and Industrial Strategy, Cm 9516, October 2017, available at: https://www.gov.uk/government/publications/draft-domestic-gas-and-electricity-tariffcap-bill

2. However capping prices raises additional challenges for the long-term development of a competitive market, particularly if reduced potential savings lower consumers' incentive to engage with the market. For a discussion of the effects of this price cap, see Deller et al. (2017a), in response to a government consultation about the enabling legislation.

a Centre for Competition Policy, University of East Anglia.

b School of Business and Economics, University of Loughborough.

c Warwick Business School, University of Warwick.

d Corresponding author. Centre for Competition Policy, University of East Anglia. E-mail: C.Waddams@uea.ac.uk.

e School of Economics, Universidad de Malaga.

f Department of Economics, University of Reading.

The Energy Journal, Vol. 42, No. 3. This is an open access article under the terms of the Creative Commons Attribution License (CC-BY), which permits use, distribution and reproduction in any medium, provided the original work is properly cited. All rights reserved. 
naïve utility-maximising models where consumers are expected to purchase a homogeneous product at a lower price.

We explore why one group of active and apparently well-motivated consumers did not accept offers of lower energy prices and reduced bills, even though it seemed easy for them to do so. Despite the evidence of this kind of inaction, policymakers have sometimes relied on a rather narrow view of the behavior of rational consumers. An example of this approach can be found in a call for evidence issued by the UK Department of Business Innovation and Skills (2015). "If you knew you had won $£ 200$ on the lottery, would you forget to claim it? Probably not. Yet consumers across the UK are effectively ignoring significant savings every year when they stick with their current providers of essential but routine services." Our investigation allows us to consider a range of non-monetary factors which are often ignored when devising policies to address consumer "inertia". Indeed, we find a number of non-monetary factors which seem influential and which help to explain the apparently weak consumer response to savings opportunities in this context, suggesting that price competition for this apparently homogeneous product may have less power than is often assumed by policymakers.

The energy sector is not only important in the individual budgets of millions of households, but, as current UK policy demonstrates, is politically sensitive and represents significant value in the overall economy. These findings therefore have important implications both for the optimal design and regulation of such markets and for the management strategies of firms operating in the energy and other industries. Consumer inaction in the face of extensive potential energy savings is widely observed, both in US States which have opened retail energy markets (Hortaçsu et al., 2017) and in the UK, where energy markets are relatively mature (Competition and Markets Authority, 2016). In the Spring of 2012, Which? (a subscription-based consumer organisation ${ }^{3}$ ) and 38 Degrees (a campaigning group) advertised an open invitation for consumers to join The Big Switch (TBS), the largest collective energy switching exercise ever conducted in the UK. Participants provided information about their energy (electricity and, where relevant, gas ${ }^{4}$ ) consumption ${ }^{5}$ which was passed on in aggregate form to the energy companies bidding in the auction. On the supply side, the auctioneers provided an open invitation to bidders, but imposed some restrictions, including geographical uniformity, ${ }^{6}$ which deterred some suppliers. Some established providers expressed concern about how participation in the auction might affect the regulator's views on prices charged to other customers. In the event, five companies, including three of the six leading providers, joined the auction. Each participating consumer then received a personalised offer based on the bid made by the winning company (Cooperative Energy - henceforth, Co-op) and was invited to accept it, but with no obligation to do so. If, for any particular consumer, there happened to be a cheaper deal available from another company on the Which? price comparison website, the consumer was shown that cheaper deal as well as the offer from Co-op. ${ }^{7}$ A small number of participants in TBS already had a deal which TBS could not improve upon: these observations have been excluded from the present analysis as we are interested in the behavior of consumers who had an opportunity to save on their existing bills but did not take up the offer.

3. Which? is the trading name of the British Consumers' Association.

4. About $85 \%$ of British households (Ofgem, 2015), and $88 \%$ of our samples, use both gas and electricity.

5. This information mirrored that required by price comparison websites to identify the best offer for a consumer.

6. In the UK market there are regional variations in tariffs, but the rules of the auction required the same price to be offered throughout the UK.

7. The geographically uniform Co-op bid was not always cheaper than some local tariffs. 
When presented with the offer(s), participants had to take little further action to complete a switch. ${ }^{8}$ Yet only just over a quarter of those who were presented with positive savings took the small step necessary to accept the offer. Even for savings of over $£ 300$ per year (around a third of the average bill), fewer than half switched, despite the fact that these participants had already actively opted into TBS, faced no additional search costs and often had characteristics which are usually associated with market engagement. We explore why so many consumers chose not to switch even when offered substantial savings in a benign switching context.

Our analysis combines energy characteristics and decision data from nearly 87,000 households with survey data for a subset of just under 7,500 participants who provided additional information about their personal characteristics and attitudes. Linking these sources of data provides a unique opportunity to observe on a large scale the decisions which consumers made about whether or not to switch.

Our data allow us to investigate switching decisions separately from the search process which consumers often face when contemplating changing supplier. ${ }^{9}$ Low rates of switching are often attributed to the deterrent effects of having to search: even with online price comparison sites available, it requires some determination to set time aside to search among many somewhat complex tariffs when, ex ante, the benefits of the search are uncertain. In the present study, the focus upon the "accept or decline offer" stage of TBS enables the isolation of a "pure" switching decision, since very little extra effort was required to accept the offer. ${ }^{10}$

We find that a wide range of factors influence a consumer's decision about whether or not to switch. The offer of a substantial monetary saving alone is often insufficient to ensure switching, even for those who said they had opted into the auction with monetary savings as a motivating factor. Other broad factors which influence the switching decision include uncertainty about various aspects of the offer(s), preferences over non-price characteristics, concerns about the switching process itself and time pressures. Many of the factors identified can be located within a rational decision-making framework, suggesting that the perceived net benefit from switching may be much less than solely the magnitude of potential monetary savings. Consequently, switching rates are likely to be substantially lower than we might initially expect, even in favourable conditions. An important policy implication is that energy markets need to be designed with such barriers in mind and in the knowledge that switching rates may be difficult to raise above a modest level.

While much of the behavior might be understood within a rational choice framework, TBS also provided some evidence of responses which may not fit rationality assumptions so well. For example, some participants saw two offers: the one from the Co-op and another (cheaper) offer that was the best from any other company on the Which? price comparison website. While more choice is conventionally regarded as desirable, in this case simply being shown two offers rather than one reduced the probability of switching, all other things being equal.

The paper proceeds as follows. Section 2 provides an overview of the literature regarding consumer behavior in energy markets. Section 3 gives a detailed description of the data and a range of descriptive statistics. Section 4 explains the econometric methods used. In section 5, we present results. Section 6 concludes and suggests some implications of our results for managers and policy makers.

8. This was simple personal information such as name, address and date of birth; and bank details so that payment could be arranged.

9. The importance of distinguishing between search costs and switching costs is emphasised by Wilson (2012).

10. See Klemperer $(1987,1995)$ for additional detail regarding different types of switching cost. 


\section{LITERATURE REVIEW}

The importance of consumer switching for the healthy functioning of markets has long been recognised (for example, see Waterson, 2003; and McFadden, 2006). In the energy market, the increasing emphasis given to consumer behavior and aggregate switching rates by regulators and politicians is evidenced by the escalating number of policy reports and initiatives on the topic: for example, Competition and Markets Authority (2016), Department of Business, Energy and Industrial Strategy (2017) and Council of European Energy Regulators (2017).

Consumer switching behavior in energy markets has been investigated in a number of survey-based academic studies. For example, Ek and Söderholm (2008), Juliusson et al. (2007), Gamble et al. (2009) and Weber et al. (2009) report survey data for parts of continental Europe, while in the UK, survey based papers include Waddams Price and Bennett (1999), Waddams Price (2004), Giulietti et al. (2005), Waddams Price and Zhu (2016), He and Reiner (2017) and Flores and Waddams Price (2018). These studies each identify anticipated monetary gains from switching as a key driver of search and switching, consistent with a rational model of consumer choice, where individuals allocate their time to different tasks according to the expected gains available. Nevertheless, these studies also find that factors beyond monetary savings influence the likelihood of switching. For example, Flores and Waddams Price (2018) and Waddams Price and Zhu (2016) report that the experience of switching in other markets positively influenced switching behavior in the electricity market. He and Reiner (2017) confirmed that non-price factors, particularly consumers' attitudes to energy, which are related both to psychological factors and political allegiance, may hinder consumers from switching even when it appears rational. While such surveys explore consumer motivations and expectations, they often rely on respondents' ability to recall and report accurately their thoughts and actions at a previous switching event. In the present study, recall issues are reduced as the switching decision is directly observed and billing information, switching behavior and the offers received by participants are recorded contemporaneously in the switching dataset.

In terms of combining billing information with socio-economic information, Kleit et al. (2012) and Hortaçsu et al. (2017) are the closest papers to the current study. Kleit et al. investigate switching behavior in Pennsylvania following the removal of residential rate caps in 2010. They find that households are more likely to switch, and do so faster, in areas with a more educated population, lower unemployment rates and higher median household incomes. However the authors rely on area level socio-economic information, rather than combining billing information with individual-level data. A similar approach is employed by Hortaçsu et al. (2017) for the Texan electricity market between 2002 and 2006. Hortaçsu et al. find that the percentage of potential energy savings realised by consumers is positively related to an area's education level and negatively related to its level of poverty. Using data from the Belgian electricity market from 2012 to 2016, and combining market share, price and advertising data with consumer surveys, Dressler and Weiergraber (2017) identify several sources of inertia. Over 65 s show a strong preference for the incumbent; some consumers are prepared to pay a premium for green energy; switching costs amount to a significant proportion of annual electricity expenditure; and supplier advertising significantly affects consumer awareness, as measured by use of price comparison websites.

Several papers estimate search and switching costs using aggregate price data rather than the decisions of individual consumers, including Giulietti et al. (2010) and Salies (2005). Giulietti et al. (2014) use a sequential search model to estimate how far price dispersion in the marketplace can be explained by search costs. Wilson and Waddams Price (2010) show that consumers may struggle to make "good" decisions in the UK electricity market, i.e. switching to the cheapest supplier; while 
Zhu (2013) cautions that non-switching in the presence of monetary savings can still be consistent with rational behavior if consumers have a preference for their existing suppliers.

As markets have matured, collective switching schemes have been introduced. In the UK, the Department for Energy and Climate Change (2013) provides a broad overview of the performance of such schemes, detailing the outcomes of 31 projects which received funding from the Cheaper Energy Together fund at the end of 2012. However, the data reported are mainly descriptive, with no quantitative analysis of the reasons for the considerable variation in the switching rates achieved (from 5.5\% to $23.1 \%$ ). Deller et al. (2017b) find a similarly low typical response to opt-in collective switching schemes, which themselves are mainly small scale, in their more thorough international review. The European Commission (2016) reports some success with collective switching schemes, particularly in Portugal, but unfortunately further details are not provided. Direct comparison of switching rates between collective and individual mechanisms is difficult because of the absence of a clearly defined control group; and because of the need to distinguish between a switching rate among the whole population of consumers and those who have already expressed their interest in switching by opting into a scheme such as that described in this paper. However, the British regulator (Ofgem, 2019) showed in a series of randomised controlled trials that collective switching schemes could increase switching rates amongst previously "disengaged" customers by more than five times compared with a control group. ${ }^{11}$ The most successful of these trials resulted in switching rates of around 30\% for those invited to participate, compared to $5 \%$ in the control group. While this rate seems similar to the levels reported in this paper, the Ofgem rates may be more remarkable, since they relate to consumers who were previously disengaged, while the consumers whose decisions are analysed in this paper often had some prior experience of switching and had taken active steps to opt in to TBS.

Regarding consumer aggregation exercises in the US, Littlechild (2008) reviews the performance of a municipal aggregation scheme in Ohio, while Loxley and Salant (2004) describe the choice of an auction mechanism used to select the default service provider in New Jersey. Opt-out switches, ${ }^{12}$ as occur in some US municipalities, gain much higher participation rates than opt-in schemes, and effectively operate as competition for a sector of the market, rather than focusing on competing for individual accounts. Ofgem ${ }^{13}$ is exploring such schemes as a longer term solution to non-engagement; however, they raise issues of privacy and default rules, and, like the government's existing price caps, are likely to require primary legislation (see Deller et al., 2017b). Our analysis of TBS opt-in campaign provides the first econometric investigation of consumer switching behavior as part of a collective switching/consumer aggregation exercise, in conjunction with substantial complementary individual survey data.

\section{DATA}

Our data combine observations of actual switching decisions from TBS with additional survey responses from a large sample of TBS participants who were contacted about nine months

11. The trials sent disengaged energy customers a variety of letters, testing whether highlighting potential savings, signposting to an exclusive tariff, and offering support with switching can increase rates of customers choosing to switch tariff. The intervention was designed to make the process of switching as simple as possible.

12. An opt-out scheme involves collectively switching consumers to an alternative deal, unless they explicitly state that they do not agree to an automatic change of supplier; this is in contrast to an opt-in collective switch where consumers themselves need to undertake some action, even if only by agreeing to the switch's terms, in order to be included.

13. Dermot Nolan's speech to Energy UK 19th October 2017 https://www.ofgem.gov.uk/system/files/docs/2017/10/ euk_final_19.10_v2.pdf 
later. Complete records of energy bill details and the offer(s) each person received as part of TBS in May 2012 were obtained for 139,644 people. Then in Spring 2013, half of this group, randomly selected, were sent a follow up survey to elicit information about factors which might have affected the probability of each individual switching energy supplier, generating 15,329 complete responses. As our research questions focus on the (non) response to financial savings, we chose to consider only those individuals who have been offered monetary savings as a result of TBS. In the discussion of our analysis we therefore focus on 119,125 TBS participants (May 2012 sample) who had received an offer of positive savings and 12,750 participants with complete responses from the Spring 2013 survey.

From those 12,750, we identified a subset whose circumstances were least complicated and who might have been considered, ex ante, as those most likely to switch and where comparison was relatively straightforward (for example only those with a single energy supplier). Our strategy was to take cases which give a naïve savings-based switching model its "best chance" and examine behavior among this "upper bound" group. To this end we applied two filters, retaining the respondents: (a) who had a single energy supplier for gas and electricity at the time of the auction; and (b) who had opted to take part in the online Direct Debit ${ }^{14}$ auction. These criteria reduced the May 2012 sample from 119,125 to 86,904. For those who subsequently participated in the Spring 2013 survey, a further filter was applied to include only respondents who identified "to save money" as one of their motivations for taking part in TBS. This left us with 7,367 survey respondents who met all three criteria.

The following summary statistics describe the characteristics of those used in the present analysis.

The first column of the first row of Table 1 shows that only $27.1 \%$ of those participants who were offered a positive saving went on to switch, despite the fact that the median saving, reported in absolute and relative terms in the fifth and sixth rows, was over $£ 100$ in the first year, representing just over $10 \%$ of those participants' pre-TBS energy bill. Given the ease of switching once the offer had been received, the relative sophistication of TBS survey participants ${ }^{15}$ and their prior action to investigate savings, this would seem to be a low take-up if energy savings are the main driver of switching.

The survey respondents (in the third and fourth columns of Table 1) were different from the larger sample in certain respects that are consistent with a higher likelihood of switching. The time and effort which they gave to respond to the survey might suggest that the relatively small amount of time and effort required to switch after receiving TBS offer was a less significant cost for them, despite the difference in the two activities. In addition, they were more likely to have referred to their actual bills (arguably a sign of greater financial awareness) and, once the filters were applied, specifically mentioned money-saving as part of their motivation for participating in TBS. Even so, almost 6 in 10 survey respondents did not switch. Table 2 provides a selection of summary statistics drawn from the survey responses which allow comparisons between respondents who did not switch and those who did.

The upper five rows of Table 2 show that in terms of household characteristics, switchers and non-switchers are reasonably similar, although switchers are more likely to be graduates and homeowners. The lower rows indicate that although switchers have a somewhat higher median in-

14. Direct Debit is the predominant payment method in Great Britain and involves monthly deductions from a bank account to spread the estimated cost of the energy evenly over the year, with an annual reconciliation from metered consumption. Note that members of this group were not necessarily paying by Direct Debit before they entered the auction.

15. Table A3.1 in the Appendix shows that those who participated in the survey were older, more highly educated and more likely to own their own home (or have a mortgage) than the typical British household. 
Table 1: Summary statistics on energy bills and TBS savings

\begin{tabular}{|c|c|c|c|c|}
\hline Variable & $\begin{array}{l}\text { Participants } \\
\text { Offered Saving } \\
\text { at TBS with } \\
\text { Complete Data } \\
\text { from } 2012\end{array}$ & $\begin{array}{c}\text { Participants } \\
\text { with Complete } \\
\text { Data from } \\
\text { 2012_Filters } \\
\text { Applied }\end{array}$ & $\begin{array}{l}2013 \text { Survey } \\
\text { Respondents } \\
\text { Offered Saving } \\
\text { at TBS }\end{array}$ & $\begin{array}{l}2013 \text { Survey } \\
\text { Respondents- } \\
\text { Filters Applied }\end{array}$ \\
\hline $\mathrm{Sv}$ & & & & \\
\hline Median bill size (actual and estimated) $(\mathfrak{l})^{5}$ & & $1168^{\circ}$ & $1161^{s}$ & 1162 \\
\hline$\%$ Using estimated bill ${ }^{2}$ & & & $21.2^{\$}$ & \\
\hline 0 Facing a & & & $13.6^{\$}$ & $16.5^{\wedge}, !$ \\
\hline Median saving offered by best supplier $(£)^{4}$ & 117.48 & & $111.48^{s}$ & $106.66^{\wedge}$ \\
\hline ledian saving as $\%$ of existing bill ${ }^{4}$ & & & & \\
\hline SI & & & & \\
\hline$e^{e b i t}{ }^{1}$ & & & $90.9^{\$}$ & \\
\hline $\begin{array}{l}\text { of single supplier households on a Dual } \\
\text { Fuel tariff }\end{array}$ & 87.1 & $87.9 *$ & 87.0 & 87.8 \\
\hline otal Number of Observations & 119,126 & 00,904 & 12,150 & /,כ50/ \\
\hline \multicolumn{5}{|c|}{$\begin{array}{l}\text { Notes: The first column covers all TBS participants who provided complete data and were offered a positive saving at } \\
\text { TBS, while the third column is the subset of this group who responded to the survey (sent to half of all participants). The } \\
\text { second column is a subset of the first formed from TBS participants who were supplied by a single supplier before TBS } \\
\text { and entered the direct debit auction. The fourth column is a subset of the second column where additionally participants } \\
\text { responded to the survey and stated saving money as one of the top three reasons for participating in TBS. } \\
\text { * Indicates the statistic for analysed participants is significantly different at the } 5 \% \text { level from the statistic for all partici- } \\
\text { pants with complete data and offered a positive saving. } \\
\text { \$ Indicates the statistic for survey respondents who were offered a positive saving is significantly different at the } 5 \% \text { level } \\
\text { from the statistics for all participants with complete data and who were offered a positive saving. } \\
\text { ^ Indicates the statistic for the analysed survey respondents is significantly different at the } 5 \% \text { level from the statistic for } \\
\text { analysed TBS participants. } \\
\text { ' Indicates the statistic for analysed survey respondents is significantly different at the } 5 \% \text { level from the statistic for all } \\
\text { participants with complete data and who were offered a positive saving. } \\
{ }^{1} \text { These are households who were paying by Direct Debit before TBS. } \\
{ }^{2} \text { This percentage combines participants who entered a "Round Amount" for their bill, suggesting they may have estimated } \\
\text { their bill, and participants who had their bill estimated by Which? on the basis of their dwelling's characteristics. Other } \\
\text { respondents are assumed to have used their actual bills. } \\
{ }^{3} \text { Single supplier households either only had an electricity connection (around } 12 \% \text { of each group) or received both their } \\
\text { electricity and gas from a single supplier before TBS. A "Dual Fuel" tariff refers to tariffs where consumers buy both their } \\
\text { electricity and gas from a single supplier as part of a combined deal. } \\
{ }^{4} \text { Tested using Mood's median test }\end{array}$} \\
\hline
\end{tabular}

come, median bill sizes are much the same. As is to be expected if there is at least some sensitivity to price, the savings offered were higher both absolutely and relative to their bills for those who switched than for those who did not; and, unsurprisingly, exit fees were more prevalent among non-switchers.

On the non-financial front, non-switchers were more likely to report other claims on their time during TBS period. In terms of the qualities of suppliers, those who switched were more likely to have a preference for the Co-op's perceived ethical/environmental/tariff type profile; fewer switchers were happy with their pre-TBS supplier's customer service. While this exploratory analysis identifies some of the potential drivers of the switching decision, we rely on a (reduced form) econometric analysis to identify more robustly the monetary and non-monetary factors associated with switching.

\section{ECONOMETRIC METHOD}

To analyse the switching decision, we used a Probit model of the likelihood to accept the offer received in TBS on the basis of both monetary considerations and non-price preferences. The 
Table 2: Comparisons between non-switchers and switchers from 2013 survey

\begin{tabular}{lcc}
\hline Variable & Non-switchers & Switchers \\
\hline Household Characteristics & & $55-64$ \\
Age group containing median age $^{1}$ & $55-64$ & 72.3 \\
\% Male & 72.1 & $64.0^{*}$ \\
\% Respondents with first degree or higher & 59.8 & $94.4^{*}$ \\
\% Respondents who fully or partly own home & 93.2 & 55.5 \\
\% Households with at least one person working full/part-time & 53.4 & $£ 35,000-39,999$ \\
Financial and Non-financial Factors & & 1161 \\
Category containing median income ${ }^{2}$ & $£ 30,000-34,999$ & $124.55^{*}$ \\
Median bill size (£) & 1162 & $11.3^{*}$ \\
Median saving (£) & 90.55 & $6.0^{*}$ \\
Median saving (\% of existing bill) & $3.4 *$ \\
\% With current exit fee & 8.7 & $8.4^{*}$ \\
\% Strongly Agree/Agree that “Timing of TBS was an especially busy period” & 24.0 & $73.6^{*}$ \\
\% Happy with pre-TBS supplier customer service & 23.0 & $55.9^{*}$ \\
\% Prefer offered supplier over existing supplier re: ethics/environment & 82.1 & $41.4^{*}$ \\
\% Prefer offered supplier over existing supplier re: tariff type & 23.7 & $\mathbf{3 , 0 8 8}$ \\
\hline Total Number of Observations & 8.0 & $\mathbf{4 , 2 7 9}$ \\
\hline
\end{tabular}

* Indicates a significant difference at the $5 \%$ level between the mean statistic for Switchers and Non-Switchers. Medians have been tested using Mood's median test. We were unable to test for a significant difference in income levels.

${ }^{1}$ Based on the 4,666 observations for which age information was available.

${ }^{2}$ Based on the 7,064 observations for which income information was available.

${ }^{3}$ These figures relate solely to people offered a positive saving as part of TBS.

dependent variable, $y_{i}$, takes a value of 1 when an individual accepted the TBS offer and a value of 0 when an individual did not accept it. For each individual the probability, $p_{i}$, of acceptance was modelled as:

$$
p_{i}=\operatorname{Prob}\left(y_{i}=1 \mid \boldsymbol{x}_{\boldsymbol{i}}\right)=F\left(\boldsymbol{x}_{\boldsymbol{i}}^{\prime} \boldsymbol{\beta}\right)
$$

Here $p_{i}$ is the probability that acceptance was observed conditional on the vector of explanatory values for individual $i, \boldsymbol{x}_{i}$. These include financial characteristics of the current and proposed supply contract, individual preferences for characteristics of the suppliers and features of their offers, and individual characteristics of the survey respondents. For the Probit model, $F($.$) is the$ Normal cumulative distribution function. We assume that when deciding whether to accept the offer (for which we use the shorthand "switch'), individual $i$ compared the utility of switching $\left(\mathrm{U}_{\mathrm{is}}\right)$ to the utility of not switching $\left(\mathrm{U}_{\mathrm{i} N S}\right)$; the probability of observing a switch by individual $i$ equalled the probability that, for individual $i$, the utility from switching exceeded the utility from not switching:

$$
\operatorname{Prob}\left(Y_{i}=1\right)=\operatorname{Prob}\left(U_{i S}>U_{i N S}\right)
$$

We assume that the unobservable utility associated with the two options could be captured by the observable variables included in the vector of explanatory variables $\boldsymbol{x}_{\boldsymbol{i}}$. We therefore modelled the difference in utility derived from switching and not switching by a set of individual-specific characteristics (e.g. gender and education), choice-specific characteristics (e.g. the respondent's view of the new supplier's environmental and ethical credentials) and characteristics which vary across both individuals and choices. We estimated the likelihood of switching using a reduced form equation of the decision to switch.

Our analysis was based on the extensive set of variables included in the 2013 survey. ${ }^{16}$ However, it is clear that those who responded to the survey were a self-selecting subsample of

16. No variables were excluded on grounds of multicollinearity, following a Variance Inflation Factor test which revealed no multicollinearity between them. 
those who took part in TBS, leading to important potential differences between the main and survey samples. To correct for any self-selection bias associated with the decision to take part in our survey we adopted the Heckman 2-stage model where, in addition to estimating an equation for the probability of switching, we also estimated an equation for the probability of taking part in the survey. The exclusion restriction imposed on the "survey participation" equation implies that the decision to participate in the survey is significantly influenced by the method through which the respondents were recruited for TBS (e.g. advertising campaign) and the numbers of reminders they were sent during the TBS campaign (as a measure of their interest to engage in the energy market), but these factors do not affect the decision to switch supplier after receiving the TBS offer. Based on the latter equation we calculated the Inverse Mills Ratio (IMR) for the probability of taking part in our survey and included it in our main regression ${ }^{17}$. We found no evidence of a statistically significant distortion arising from self-selection; however, we recognise that any conclusions and policy recommendations driven by the results obtained from the responses of these potentially more engaged consumers might overestimate the likelihood of switching within the general population of consumers, both of TBS participants and more widely.

A preliminary depiction of the relationship between the frequency of switching and the amount of savings offered is shown in Figure 1.

Figure 1: Switching rates by size of annual saving (£)

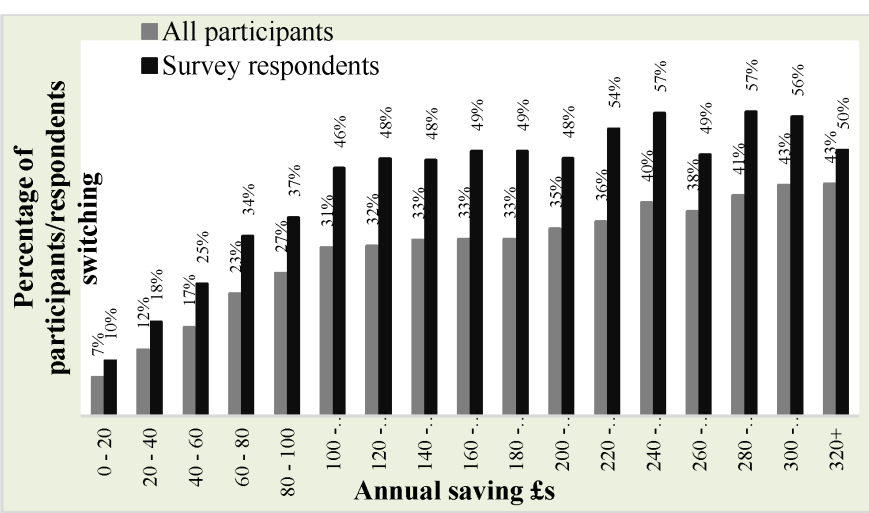

For both the main sample and for the survey sample, there is a clear correlation between the size of saving offered by TBS and the likelihood of switching. However, the rate of increase in the percentage of respondents switching slows at savings amounts higher than $£ 100$. For the main sample, moving from the category of $£ 0-20$ in savings to that of $£ 100-120$ increases the probability of switching by 24 percentage points, while moving from the category of $£ 100-120$ to that of $£ 300$ 320 increases the probability by only 12 percentage points. The corresponding figures for the survey sample are 36 and 10 percentage points respectively. This led us to adopt a quadratic specification for the (continuous) saving variable in our Probit model. ${ }^{18}$ The average marginal effects presented in Table 3 have been calculated taking into account the quadratic treatment of this variable.

17. Technical details of the econometric methodology discussed in this section are provided in Appendix 4, while details of the regression resulting in the IMR are given in table A3.2.

18. The respondents' current energy bill and the alternative energy cost offered by the new TBS offer were initially included separately in the regression, but a test on the restriction of equal coefficients for these two variables revealed it was possible to use their difference (which we label saving amount) directly in our Probit model. 
In addition to the savings offered as part of TBS process, we also included the minimum amount of savings which our respondents said they had required in order to switch. While including such information helped us to understand the cost-benefit evaluation undertaken by our respondents, the inclusion of the minimum required saving variable created an endogeneity problem, as it is conceivable that unobserved factors which affected their decision to switch in 2012 might also affect the required savings to switch stated in 2013. These factors could, for instance, include their attitude towards the uncertainty associated with moving to a different supplier. Indeed, one might expect individuals who are more "cautious" to be both less likely to switch and require more money to be persuaded to switch.

Due to the potential endogeneity of the minimum required saving variable, our Probit model was estimated using conditional maximum likelihood estimation, ${ }^{19}$ an instrumental variable method. This method involves the joint estimation of two equations, the first of which has the potentially endogenous variable as the dependent variable. The predicted values of the endogenous variable were included as regressors in the main Probit model (i.e. as part of $\boldsymbol{x}_{\boldsymbol{i}}$ in equation (1)). Following this procedure to correct for potential endogeneity, the magnitude and sign of the main estimated effects were not substantially affected, compared to the simple Probit model with no correction for endogeneity; nevertheless, we have included the correction in the regression reported in Table 3.

Lastly, it seemed possible that unobserved factors might affect both the probability of being presented with two (rather than just one) offers and the decision to switch. In order to account for this possibility, we used a recursive Probit model where in a first stage we modelled the probability of being presented with two offers and then we modelled the probability of switching conditional on the number of offers made to the participant, in addition to all the other factors which could have affected the switching decision..$^{20}$

When considering the different explanatory factors included in our reduced form analysis we would expect that positive monetary incentives, such as higher savings, or a motivation to save money as part of the TBS process, would increase the probability to switch, while we would expect the opposite effect from disincentives such as having to pay an exit fee or losing other benefits as a result of switching. We would also expect that the likelihood of switching would be reduced by uncertainty about the actual size of the savings or about the switching process. A negative effect would also be expected as result of constraints on the respondents' time. Another key factor in the decision to switch has been identified in the literature as the existence of heterogeneous preferences for different suppliers and their brands (see e.g. Dubé et al., 2010). We account for these effects by including in our analysis the respondents' preferences for characteristics and offers of their current supplier and for those of the new "proposed" supplier. We would expect that a preference for the characteristics of the current supplier would reduce the probability of switching, while the opposite would hold if the characteristics of the new supplier were preferred, or if the respondents were dissatisfied with the service provided by their current supplier.

\section{RESULTS}

The econometric approach described in the previous section was used to explore the role of a wide range of financial and non-financial variables in individuals' switching decisions. Table 3

19. Technical details about this estimation approach are provided in Appendix 4.

20. In Appendix 2, we report the results of separate regressions for those shown one or two offers at TBS; although a likelihood ratio test indicated that separate regressions should be run for those shown one offer and those shown two offers, the main results are not qualitatively different. 
Table 3: Selected average marginal effects on the probability of switching energy supplier at TBS

\begin{tabular}{|c|c|c|c|c|}
\hline \multirow[b]{2}{*}{$\begin{array}{l}\text { Switching } \\
\text { Factor }\end{array}$} & \multirow[b]{2}{*}{ Variable } & \multicolumn{3}{|c|}{ Average Marginal Effects } \\
\hline & & $\begin{array}{c}\text { Filtered } \\
\text { Survey } \\
\text { Respondents }\end{array}$ & $\begin{array}{c}\text { Survey } \\
\text { respondents } \\
\text { with positive } \\
\text { savings }\end{array}$ & $\begin{array}{c}\text { Excluded } \\
\text { survey } \\
\text { respondents } \\
\text { with positive } \\
\text { savings }\end{array}$ \\
\hline \multirow{5}{*}{$\begin{array}{l}\text { Monetary } \\
\text { Savings }\end{array}$} & 1. Saving amount of the best offer ( $£ 10$ units) & $0.016^{* * *}$ & $0.014 * * *$ & $0.013 * * *$ \\
\hline & 2. Has an Exit Fee & $-0.173 * * *$ & $-0.158 * * *$ & $-0.125^{* * *}$ \\
\hline & 3. No other penalty/loss of benefits if switch supplier & $0.054 * * *$ & $0.063 * * *$ & $0.086^{* * *}$ \\
\hline & 4. Top 3 factor persuading to switch: Large enough saving & $-0.040^{* * *}$ & $-0.020 * *$ & -0.003 \\
\hline & $\begin{array}{l}\text { 5. Stated minimum required saving to switch (Spring } \\
2013, £ 1 \text { units) }\end{array}$ & $-0.001 * * *$ & $-0.001 * * *$ & $-0.001 * * *$ \\
\hline \multirow[t]{6}{*}{$\begin{array}{l}\text { Non-Price } \\
\text { Preferences }\end{array}$} & $\begin{array}{l}\text { 6. Electricity/energy supplier before TBS: Co-Operative } \\
\text { Energy }\end{array}$ & $0.098 * *$ & $0.154 * * *$ & $0.246 * * *$ \\
\hline & 7. Prefers existing supplier re: tariff type & $-0.149 * * *$ & $-0.141 * * *$ & $-0.131 * * *$ \\
\hline & $\begin{array}{l}\text { 8. Prefers offered supplier on ethical/environmental } \\
\text { grounds }\end{array}$ & $0.115 * * *$ & $0.111 * * *$ & $0.104 * * *$ \\
\hline & 9. Prefers offered supplier re: tariff type & $0.188 * * *$ & $0.178 * * *$ & $0.162 * * *$ \\
\hline & 10. Prefers offered supplier for "Other" reason & $0.118 * * *$ & $0.101 * * *$ & $0.083 * * *$ \\
\hline & 11. Top 3 factor to switch: ethical/environmental reasons & $0.024 *$ & 0.005 & -0.011 \\
\hline \multirow[t]{6}{*}{$\begin{array}{l}\text { Uncertainty/ } \\
\text { Preparedness }\end{array}$} & $\begin{array}{l}\text { 12. Confidence in accuracy of TBS saving (continuous } \\
\text { scale } 0 \text { to } 1 \text { ) }\end{array}$ & 0.031 & $0.040 * * *$ & $0.040^{*}$ \\
\hline & 13. Energy bill estimated by Which & $-0.070 * * *$ & $-0.070 * * *$ & $-0.084 * * *$ \\
\hline & 14. Respondent states bill as 'Round' amount & $-0.048 * * *$ & $-0.046 * * *$ & $-0.048 * *$ \\
\hline & $\begin{array}{l}\text { 15. Unsure if other penalty/loss of benefits if switch } \\
\text { supplier }\end{array}$ & $-0.052 * * *$ & $-0.052 * * *$ & -0.029 \\
\hline & 16. Top 3 factor to switch: confidence in getting best deal & $0.023 * *$ & $0.031 * * *$ & $0.032 * * *$ \\
\hline & 17. Shown two offers & $-0.060 * * *$ & $-0.051 * * *$ & $-0.049 * * *$ \\
\hline Concerns with & 18. Worried re: "Other" issues & $-0.104 * * *$ & $-0.101 * * *$ & $-0.090 * * *$ \\
\hline Switching & 19. Additional help wanted: phone support & $-0.057 * * *$ & $-0.030 * *$ & 0.000 \\
\hline \multirow[t]{3}{*}{ Process } & 20. Additional help wanted: simpler switching process & $-0.112 * * *$ & $-0.109 * * *$ & $-0.107 * * *$ \\
\hline & 21. Additional help wanted: something else & $-0.069^{* * *}$ & $-0.068 * * *$ & $-0.065^{* * *}$ \\
\hline & 22. Top 3 factor to switch: Quick \& easy switching process & $0.025 *$ & $0.018 *$ & 0.009 \\
\hline \multirow[t]{5}{*}{ Time Pressures } & 23. Worried switching would be time consuming & $0.050 * * *$ & $0.055 * * *$ & $0.062 * * *$ \\
\hline & 24. TBS was a very busy period: Strongly Agree & $-0.228 * * *$ & $-0.204 * * *$ & $-0.173 * * *$ \\
\hline & 25. TBS was a very busy period: Agree & $-0.106^{* * *}$ & $-0.104 * * *$ & $-0.094 * * *$ \\
\hline & 26. TBS was a very busy period: Disagree & $0.036 * * *$ & $0.034 * * *$ & $0.027 * *$ \\
\hline & 27. TBS was a very busy period: Strongly Disagree & -0.014 & 0.001 & 0.024 \\
\hline Respondent & 28. Number of people in household: One & $0.037 * * *$ & $0.040 * * *$ & $0.042 * * *$ \\
\hline Characteristics & 29. Highest Educational Qualification: Masters/PhD & $0.026^{* *}$ & $0.020 * *$ & 0.007 \\
\hline Other & 30. IMR for survey response & 0.137 & 0.152 & 0.087 \\
\hline $\mathbf{N}$ & & 7,367 & 12,750 & 5,383 \\
\hline
\end{tabular}

Notes: * indicates significance at the $10 \%$ level, $* *$ indicates significance at the $5 \%$ level and $* * *$ indicates significance at the $1 \%$ level. The current table focuses on variables that were statistically significant. A wide range of additional variables were included in the regression, including: payment method before TBS, respondent gender, household tenure, employment status of household members, whether in receipt of a fuel related benefit and communication with existing supplier triggered by TBS. In particular, dummy variables for electricity supply regions and median household income in a respondent's postcode area were included and generally found to be statistically insignificant. Additional dummies for extra options beyond those listed in the current table were included for: factors that would persuade a respondent to switch, preferences between previous and offered suppliers, worries about the switching process, additional help wanted, number of household members and highest educational qualification obtained. Details of the complete regression results are available on request. Default categories for reported dummy variables. 2: No Exit Fee; 3 and 14: Has a penalty/loss of benefits if switch; 4, 11, 16 and 22: Listed factor not in the top 3 factors that would persuade the respondent to switch in the future; 6: Electricity/energy supplier before TBS-All energy suppliers other than Co-Operative Energy and EBICo; 7 to 10: Indifferent between existing and offered supplier on stated dimension; 13 and 14: Respondent used actual bill and stated 'Non-Round' amount; 17: Shown one offer; 18 and 23: Not worried about stated issue; 19 to 21: The form of additional help stated was not required; 24 to 27: Neither agree nor disagree with the statement "TBS was a very busy period"; 28: Two people in household; 29: Highest educational qualification - first degree or equivalent

Observations dropped by regressions: No observations were recorded for the postcode area income category $£ 75,000-80,000$. 
reports the average marginal effects of key explanatory variables on the probability of switching energy supplier, using information from the original TBS data and from our survey. ${ }^{21}$ The role of savings in incentivising switching is placed in the context of the perceived uncertainties and other non-financial considerations involved in the switching decision.

We present the variables in broad categories which might affect the likelihood of switching, but which sit largely within a rational choice framework: savings offered, non-price preferences, uncertainty on the part of the participant, concerns with the switching process, time pressures and characteristics of the participant themselves. While such subdivisions are inevitably somewhat arbitrary, they enable a more manageable discussion of the results, whose nature and size are not affected by the categorisation. Most of the variables are relevant to the development of general policies towards consumer switching in energy, but the interpretation of some is specific to the TBS experience, in particular: variable 6, being a Co-op customer before TBS; variables 24 to 27 which refer specifically to the TBS period; and variable 17, being shown two offers. We take the specifics of the exercise into account in our discussion of each of these categories below.

Table 3 summarises the key results for the respondents identified by the filters discussed in section 3 (filtered survey respondents in column 1), alongside the results for the whole group of survey respondents who were presented with the offer of positive savings (column 2), and for the respondents who were excluded from our analysis (column 3). For the majority of the variables considered in our analysis we notice that the estimated average marginal effects are significant (to a similar extent) across the 3 groups of survey respondents, but the magnitude of the average marginal effects is higher for the filtered participants, except for the impact of consumers who were already supplied by Coop energy. Also, the average marginal effect associated with the desire for confidence in getting the best deal is higher for the excluded respondents (and for the survey respondents overall), possibly reflecting the complexity of working out the "best" deal for consumers who are not driven primarily by financial considerations.

Having considered in general terms the results for all survey respondents and for those who did not meet our criteria for a high propensity to switch, we now discuss in more detail the results for the group of respondents that we consider as most likely to switch given their interest in financial gains and the relative simplicity of their switching process.

Dealing with each category in turn, monetary savings continue to exert an important influence on the probability of switching: an increase of $£ 10$ in the saving offered at TBS is associated with a 1.6 percentage point increase in the probability of switching. ${ }^{22}$ However the results illustrate why an offer of monetary savings alone is insufficient to guarantee switching. The presence of an exit fee from a consumer's existing energy supplier is associated with an average reduction in the probability of switching of 17.3 percentage points. In monetary terms this corresponds to a required increase in savings of about $£ 120^{23}$ in order to renege on the existing contract and having to pay an exit fee, which was on average about $£ 50^{24}$ at the time of TBS. From our results it therefore appears

21. The marginal effects of only those variables which are available for these respondents from the TBS exercise itself are reported in Table A1.1.

22. The reported marginal effect of the saving amount reflects the quadratic treatment of this term in the Probit model.

23. This is calculated as the ratio of the estimated coefficient (N.B. not the marginal effect reported in Table 3) associated with the dummy variable for the exit fee and the estimated coefficients associated with the level of savings (taking into account the quadratic treatment of this variable).

24. While some companies were charging up to $£ 100$ exit fees, $£ 25-£ 30$ was more typical, see: http://www.thisismoney. co.uk/money/bills/article-2934318/Don-t-let-exit-fee-switching-energy-deals-50-levy-potential-savings-eye-popping.html . 
that the existence of an exit fee has a disproportionate deterrent effect on switching, perhaps reflecting "loss aversion". ${ }^{25}$

Variable 4 relates to a question asking about factors which would induce switching in the future. A respondent who reported that one of these factors was a "large enough saving" may have been indicating that they required a particularly large saving to switch supplier, and/or that the saving presented at TBS was insufficient. So we see that headline monetary savings themselves may have been moderated by other considerations, including exit fees and other penalties and the respondent's own evaluation of financial rewards.

A variety of non-financial preferences and characteristics are captured by variables 6 to 11. Although in comparison with other consumer goods energy may appear to be homogenous, it is clear that respondents had preferences over suppliers beyond the price charged. For example, preferring the ethical/environmental stance of an offered supplier to that of the respondent's existing supplier is associated with an increase in switching probability of 11.5 percentage points (compared to the base case of indifference between suppliers regarding this factor). Since the Co-op had a positive ethical and environmental reputation at the time of TBS, it is not surprising that those who were influenced by ethical and environmental reasons (variables 8 and 11) were more likely to accept the offer (although it may be hard to separate this entirely from the fact that consumers already with the Co- op were effectively only switching to a different tariff and faced reduced uncertainty about the service they would receive).$^{26}$ Consumers who were uncertain about the size of saving were less likely to switch for a given "expected" gain, and this is reflected in variables 12 through 17. Greater confidence in the accuracy of the offered savings increases the chances of switching, while not knowing the exact amount of the bill or whether exit penalties exist may be interpreted as lower confidence in the accuracy of any saving offered and may thereby have negative effect on the probability of switching.

We have also included under uncertainty the negative effect of being shown two offers in TBS rather than one (variable 17). One possible interpretation is that being shown two offers may have prompted some participants to wonder whether there might be other (possibly better) deals in the wider market, either now or in the near future, encouraging postponement of a decision. Another is that being presented with two offers may indicate that there was another pre-existing cheap offer on the market, which the participant had already "ignored', suggesting greater inertia. ${ }^{27}$ However, the unique circumstances of TBS, where participants expected only one offer and received two, may mean that any interpretations do not necessarily generalise to other switching situations.

There may have been uncertainties not just about the gains to be realised, but also about the switching process itself, and these are captured by variables 18 to 23 . This group of variables suggest that higher "anxiety" and/or effort costs are associated with a lower probability of switching at TBS, while the desire for a quick and easy switching process (possibly facilitated by the support and auctioning system put in place by Which?) increases the probability of switching. The size

25. Loss aversion is the idea that losses weigh more heavily in consumer decisions than corresponding gains, and numerous studies have suggested a ratio of between 1.5 and 2.5 to 1 , similar to our results (see Kahneman, 2011, p.284)

26. Of the 22 filtered survey respondents who were already with Co-Op before TBS and switched through TBS, 4 changed to other suppliers (equivalent to "external switching" as used by the Council of European Energy Regulators, 2018) and 18 remained with Co-Op after TBS, equivalent to "internal switching". At least 3 of these internal switchers chose Co-Op even though a larger saving was available from an alternative supplier. An existing Co-Op customer might have chosen to make such an "internal switch" through TBS because they were offered a special deal in the auction.

27. We thank an anonymous referee for this suggestion. 
of these positive effects is generally smaller than the negative impact of other concerns about the switching process.

Another possible reason for not switching, even when offered substantial savings and sent several reminders, is pressure on consumers' time, such that even the small amount of time and attention needed to accept the offer felt excessive at that moment. The effects of variables 24 to 27 , taken together, are as might be expected in a rational choice framework: individuals who reported greater time pressure around TBS were less likely to switch. For example, strongly agreeing that TBS came during a busy period is associated with a 23-percentage point reduction in switching probability. The sign of the average marginal effect for variable 27 is unexpected, although not statistically significant. We therefore conclude that time pressure contributes to understanding unresponsiveness to money saving offers.

Once the specific characteristics and contexts of a respondent's choice decision are controlled for, few socio-economic characteristics are associated with the probability of switching..$^{28}$ Gender, housing tenure, receipt of fuel related benefits, regional location and median income in the respondents" postcode area all have statistically insignificant relationships with the probability of switching. Two exceptions were education and household size. Those with postgraduate qualifications were more likely to switch, as were single person households. The 3.7 percentage point increase in the probability of switching associated with being a single person household might reflect the greater simplicity of decision making when there is no need to reach agreement with other household members. Moreover, a single individual can more easily identify the benefits that would accrue to them personally from switching and balance these against the (individually incurred) efforts involved.

We summarise the story told by these results as follows. When all we have are data about monetary savings and penalties, even when supplemented by a limited set of variables that proxy uncertainty or lack of confidence, households appear to leave a considerable amount of money on the table in the British retail energy market. However, a number of other factors, such as non-price preferences, time pressures and concerns about the switching process itself, appear to be affecting consumers' behavior. The "enhanced" respondent model is not perfect and influences from some variables are possibly still not identified - including, perhaps, some heuristics or biases that might be conventionally regarded as "irrational". Nevertheless, the model derived from our survey contributes to explaining why financial rewards alone may fail to induce switching, even among people who are well-educated and more engaged than most within the retail energy market.

\section{CONCLUSION}

TBS provided a unique opportunity to observe the detailed decisions and circumstances of a large group of energy consumers faced with a real choice of providers in the residential energy market. These consumers were generally more pro-active in this market than the average householder, as demonstrated by their participation in TBS itself, and within this group we have focused on those who joined the exercise to save money and responded to a follow-up survey. Consequently, our findings could be viewed as an upper bound on engagement in the UK energy market. The sample is self-selected, as individuals took several active steps to participate in the auction and respond

28. However recall that our sample is far from representative of the population as a whole where variations in socio-economic characteristics are likely to be larger and hence may have effects on the probability of switching which we do not see in our self-selected sample. 
to the survey, and they possess underlying traits associated with more activity/engagement than the general population.

While we find that switching is positively correlated with the savings offered to participants, the raw data clearly demonstrate that the prospect of substantial savings is not by itself sufficient to induce a majority of participants to switch, despite the small additional effort required and several reminders from Which?. A range of non-price factors-various sources of uncertainty, the non-monetary characteristics of different offers, concerns about the switching process and time pressures when TBS occurred - are all associated with the switching decision. Some other features, such as the seemingly disproportionate weight attached to exit fees and the negative impact of seeing two offers rather than one, may have elements of behavioral bias; but most of the factors we identify are consistent with consumers making a largely "rational" decision when declining to switch, even if this results in substantial monetary savings apparently being left on the table. Moreover the relationship between switching and savings levels off, so that increased savings have little additional effect on the probability of switching beyond one hundred pounds per year.

Our findings have some important implications for policy makers and managers. The significant role of non-financial factors means that switching cannot be relied on to put all consumers on the cheapest deal for them. Indeed, our results suggest that some consumers consciously choose to remain with more expensive suppliers due to non-price preferences. These non-price preferences confirm that consumers do not regard energy as a homogeneous product, despite the view of many analysts. So our second policy conclusion is that actions which automatically move consumers to a cheaper supplier may reduce utility for at least some consumers, since they do not regard suppliers as completely interchangeable. Management which can differentiate its supply/service offering may be able to create considerable value - at least for some consumers - even though the gas or electricity itself is homogeneous.

In terms of process, the restrictions on switching fees introduced by European Commission's Directive on Clean Energy (2019), Article 12, are supported by the disproportionate effect of exit fees, our third conclusion. Our fourth conclusion is that opt-in collective switching processes, such as TBS, do not constitute a panacea in attracting a wide variety of consumers to switch to cheap energy deals. These collective switches rely on a different kind of consumer engagement, both to "opt in" to the process and to accept the auction offer. Those who opted into this auction displayed characteristics which are typically associated with higher engagement (see e.g. Competition and Markets Authority, 2016), but they still "left money on the table" by not switching after the offer had been made.

However, the results confirm that financial gains are positively associated with switching, so policies which restrict potential savings, including price caps, are likely to reduce switching rates. Indeed, there is a danger that such policies may foster disengagement if consumers suppose that the regulator is looking after their interests so that they need not concern themselves. On the other hand, the proportion of TBS participants still not switching suggests that relying substantially on consumers to drive margins down to competitive levels is likely to prove disappointing to policymakers.

\section{ACKNOWLEDGMENTS}

We are very grateful to Which? for making available the data for this study and working with us on the analysis, and to the Economic and Social Research Council for funding the initial stages of this study through its support for the Centre for Competition Policy (CCP) at the University of East Anglia (grant RES-578-28-0002); David Deller and Catherine Waddams also received 
support from the UK Energy Research Centre under Phase 3 (grant EP/L024756/1); Monica Giulietti received financial support from the EPSRC (grants EP/N001745/1, EPR062258/1 and EP/ K002228) and from UKERC (grant FF3/3); and Graham Loomes received support from the Economic and Social Research Council's funding of the Network for Integrated Behavioural Science (grants ES/K002201/1 and ES/P008976/1).

We thank participants at seminars at CCP, Which?, the University of Toulouse, 6th Mannheim Energy Conference and the Cambridge Energy Policy Research Group, and a number of colleagues, especially Jeremy Smith, for their helpful comments.

\section{REFERENCES}

Cameron, A.C. and P.K. Trivedi (2005). Microeconometrics: Methods and Applications. Cambridge University Press. https:// doi.org/10.1017/CBO9780511811241.

Competition and Markets Authority (2016). Energy Market Investigation Final Report. https://assets.publishing.service.gov. uk/media/5773de34e5274a0da3000113/final-report-energy-market-investigation.pdf.

Council of European Energy Regulators (2017). Consumer Empowerment. https://www.ceer.eu/documents/104400/5937686/ Consumer+Empowerment/46be56b4-6b81-e413-5ae0-20f8beb0cbf5.

Council of European Energy Regulators (2018). Performance of European Retail Markets in 2017 CEER Monitoring Report. https://www.ceer.eu/documents/104400/-/-/31863077-08ab-d166-b611-2d862b039d79.

Department of Business, Energy and Industrial Strategy (2017). Draft Domestic Gas And Electricity (Tariff Cap) Bill, October, Cm 9516. https://www.gov.uk/government/publications/draft-domestic-gas-and-electricity-tariff-cap-bill.

Department of Business, Innovation and Skills (2015). Call for Evidence: Switching Principles. October, BIS/15/533. https:// assets.publishing.service.gov.uk/government/uploads/system/uploads/attachment_data/file/469998/BIS-15-533-call-forevidence-switching.pdf.

Department for Energy and Climate Change (2013). Helping Customers Switch: Collective Switching and Beyond. https:// www.gov.uk/government/publications/helping-customers-switch-collective-switching-and-beyond.

Deller, D., E. Errington, A. Fletcher, M. Hviid, D. Reader and C. Waddams (2017a). Response to Business, Energy and Industrial Strategy Committee: Pre-legislative scrutiny of the draft Domestic Gas and Electricity (Tariff Cap) Bill inquiry. http://competitionpolicy.ac.uk/documents/8158338/16525214/6+CCP+response+to+BEIS+Committee+Energy+Price+Cap+Inquiry.pdf/236d419d-d157-2e0e-2eea-0923d75dd035.

Deller, D., P. Bernal, M. Hviid and C. Waddams Price (2017b). Collective Switching and Possible Uses of the Disengaged Consumer Database, Centre for Competition Policy. http://competitionpolicy.ac.uk/documents/8158338/19064125/ Collective+Switching+Report+-+August+2017.pdf/127c78b6-faad-4496-b198-f56862230896.

Dressler, L. and S. Weiergraber (2019). Alert the Inert! Switching Costs and Limited Awareness in Retail Electricity Markets, mimeo. https://sweiergr.github.io/_downloads/electricity_inertia.pdf.

Dubé, J-P, G.J. Hitsch and P.E. Rossi (2010). "State dependence and alternative explanations for consumer inertia." Rand Journal of Economics 41(3): 417-445. https://doi.org/10.1111/j.1756-2171.2010.00106.x.

Ek, K. and P. Söderholm (2008). "Households" switching behavior between electricity suppliers in Sweden.” Utilities Policy 16(4): 254-261. https://doi.org/10.1016/j.jup.2008.04.005.

European Commission (2016). Second consumer market study on the functioning of the retail markets for consumers in the EU. Final report. https://op.europa.eu/en/publication-detail/-/publication/bb415e9e-6154-11e7-951d-01aa75ed71a1/ language-en.

European Union (2019). Directive (EU) 2019/944 of the European Parliament and of the Council of 5 June 2019 on common rules for the internal market for electricity and amending Directive 2012/27/EU (recast). https://eur-lex.europa.eu/ legal-content/EN/TXT/PDF/?uri=CELEX:32019L0944\&from=EN.

Flores, M. and C. Waddams Price (2018). "The Role of Attitudes and Marketing in Consumer Behaviours in the British Retail Electricity Market.” The Energy Journal 39(4): 153-179. https://doi.org/10.5547/01956574.39.4.mflo.

Gamble, A., E.A. Juliusson and T. Gärling (2009). "Consumer attitudes towards switching supplier in three deregulated markets.” The Journal of Socio-Economics 38(5): 814-819. https://doi.org/10.1016/j.socec.2009.05.002.

Giulietti, M., J. Otero and M. Waterson (2010). "Pricing behaviour under competition in the UK electricity supply industry." Oxford Economic Papers 62(3): 478-503. https://doi.org/10.1093/oep/gpp029.

Giulietti, M., C. Waddams Price and M. Waterson (2005). "Consumer Choice and Competition Policy: A Study of UK Energy Markets.” Economic Journal 115(506): 949-968. https://doi.org/10.1111/j.1468-0297.2005.01026.x. 
Giulietti, M., M. Waterson and M.R. Wildenbeest (2014). "Estimation of Search Frictions in the British Electricity Market." Journal of Industrial Economics 62(4): 555-590. https://doi.org/10.1111/joie.12062.

Greene, W.H. (2011). Econometric Analysis, seventh edition. Pearson.

He, X and D. Reiner (2017). "Why Consumers Switch Energy Suppliers: The Role of Individual Attitudes." The Energy Journal 38(6): 25-53. https://doi.org/10.5547/01956574.38.6.hxia.

Hortaçsu, A., S.A. Madanizadeh and S.L. Puller (2017). "Power to Choose? An Analysis of Consumer Inertia in the Residential Electricity Market." American Economic Journal: Economic Policy 9(4): 192-226. https://doi.org/10.1257/ pol.20150235.

Juliusson, E.A., A. Gamble and T. Gärling (2007). "Loss aversion and price volatility as determinants of attitude towards and preference for variable price in the Swedish electricity market." Energy Policy 35(11): 5953-5957. https://doi. org/10.1016/j.enpol.2007.06.019.

Kahneman, D. (2011). Thinking, Fast and Slow, New York: Farrar, Straus and Giroux.

Kleit, A.N., A.V. Shcherbakova and X. Chen (2012). "Restructuring and the retail residential market for power in Pennsylvania.” Energy Policy 46: 443-451. https://doi.org/10.1016/j.enpol.2012.04.008.

Klemperer, P. (1987). "Markets with Consumer Switching Costs.” Quarterly Journal of Economics 102(2): 375-394. https:// doi.org/10.2307/1885068.

Klemperer, P. (1995). "Competition when Consumers have Switching Costs: An Overview with Applications to Industrial Organization, Macroeconomics, and International Trade.” Review of Economic Studies 62(4): 515-539. https://doi. org/10.2307/2298075.

Littlechild, S. (2008). "Municipal aggregation and retail competition in the Ohio energy sector." Journal of Regulatory Economics 34: 164-194. https://doi.org/10.1007/s11149-008-9067-y.

Loxley, C. and D. Salant (2004). "Default Service Auctions.” Journal of Regulatory Economics 26: 201-229. https://doi. org/10.1023/B:REGE.0000038932.72922.ef.

McFadden, D. (2006). "Free markets and fettered consumers." American Economic Review 96(1): 3-29. https://doi. org/10.1257/000282806776157542.

Ofgem (2008). Energy Supply Probe-Initial Findings Report. https://www.ofgem.gov.uk/sites/default/files/docs/2008/10/ energy-supply-probe---initial-findings-report.pdf.

Ofgem (2014). Retail Market Review—Baseline Consumer Survey. https://www.ofgem.gov.uk/ofgem-publications/89113/ ofgemrmrbaselinefinalpdf-pdf.

Ofgem (2015). Appendices for insights paper on households with electric and other non-gas heating. https://www.ofgem.gov. $\mathrm{uk} / \mathrm{sites} /$ default/files/docs/appendices_for_insights_paper_on_households_with_electric_and_other_non-gas_heating_0. pdf.

Ofgem (2019). Ofgem's collective switch trials. https:/www.ofgem.gov.uk/system/files/docs/2019/09/collective_switch_ trials_final_report_final.pdf

Salies, E. (2005). A Measure of Switching Costs in the GB Electricity Retail Market. MPRA Paper No. 28255.

Waddams Price, C. (2004). Spoilt for Choice? The Costs and Benefits of Opening UK Residential Energy Markets. Centre for Competition and Regulation Working Paper 04-1. http://competitionpolicy.ac.uk/documents/8158338/8199514/ccp4-1. pdf/6fe9c0c3-f5fe-4b95-8805-57d1ff6e8ba2.

Waddams Price, C. and M. Bennett (1999). "New gas in old pipes: opening the UK residential gas market to competition." Utilities Policy 8(1): 1-15. https://doi.org/10.1016/S0957-1787(99)00010-7.

Waddams Price, C. and M. Zhu (2016). "Empirical Evidence of Consumer Response in Regulated Markets." Journal of Competition Law and Economics 12(1): 113-149. https://doi.org/10.1093/joclec/nhv041.

Waterson, M. (2003). "The role of consumers in competition and competition policy." International Journal of Industrial Organization 21(2):129-150. https://doi.org/10.1016/S0167-7187(02)00054-1.

Weber, S., A. Baranzini and E. Fragniere (2009). "Consumers" choices among alternative electricity programmes in Geneva—an empirical analysis.” International Journal of Global Energy Issues 31(3/4): 295-309. https://doi.org/10.1504/ IJGEI.2009.027643.

Wilson, C.M. (2012). "Market frictions: A unified model of search costs and switching costs." European Economic Review 56(6): 1070-1086. https://doi.org/10.1016/j.euroecorev.2012.05.007.

Wilson, C.M. and C. Waddams Price (2010). "Do consumers switch to the best supplier?" Oxford Economic Papers 62(4): 647-668. https://doi.org/10.1093/oep/gpq006.

Zhu, M. (2013). "Searching and Switching Across Markets: Is Consumer "Inertia” the Result of a Mistake or a Preference?" Chapter 4 in Mehta, J. (ed.) Behavioral Economics in Competition and Consumer Policy, Norwich, Norfolk: ESRC Centre for Competition Policy. 
APPENDICES

\section{APPENDIX 1: SWITCHING PROBABILITIES}

\section{Table A1.1: Selected average marginal effects on the probability of switching energy supplier at TBS using TBS data only}

\begin{tabular}{|c|c|c|c|c|c|}
\hline \multirow[b]{2}{*}{$\begin{array}{l}\text { Switching } \\
\text { Factor }\end{array}$} & \multirow[b]{2}{*}{ Variable } & \multirow[b]{2}{*}{$\begin{array}{c}\text { (1) All } \\
\text { Participants with } \\
\text { Positive Savings }\end{array}$} & \multirow[b]{2}{*}{$\begin{array}{c}\text { (2) } \\
\text { Filtered } \\
\text { Participants }\end{array}$} & \multicolumn{2}{|c|}{ Average Marginal Effects } \\
\hline & & & & $\begin{array}{c}\text { (3) All Survey } \\
\text { Respondents with } \\
\text { Positive Savings }\end{array}$ & $\begin{array}{c}\text { (4) } \\
\text { Filtered Survey } \\
\text { Respondents }\end{array}$ \\
\hline $\begin{array}{l}\text { Monetary } \\
\text { Savings }\end{array}$ & $\begin{array}{l}\text { 1. Saving amount of the } \\
\text { best offer ( } £ 10 \text { units) } \\
\text { 2. Has an Exit Fee }\end{array}$ & $\begin{array}{c}0.012 * * * \\
-0.205^{* * *}\end{array}$ & $\begin{array}{c}0.012 * * * \\
-0.206 * * *\end{array}$ & $\begin{array}{c}0.013 * * * \\
-0.320 * * *\end{array}$ & $\begin{array}{c}0.015 * * * \\
-0.317 * * *\end{array}$ \\
\hline $\begin{array}{l}\text { Uncertainty or } \\
\text { Preparedness }\end{array}$ & $\begin{array}{l}\text { 3. Energy bill estimated } \\
\text { by Which } \\
\text { 4. Respondent states bill } \\
\text { as 'Round' amount }\end{array}$ & $-0.179 * * *$ & $-0.172 * * *$ & $-0.125 * * *$ & $-0.124 * * *$ \\
\hline Other & 5. Shown two offers & $-0.057 * * *$ & $-0.074 * * *$ & $-0.104 * * *$ & $-0.141 * * *$ \\
\hline $\mathbf{N}$ & & 119,125 & 86,888 & 12,748 & 7,363 \\
\hline
\end{tabular}

Notes: * indicates significance at the $10 \%$ level, ** indicates significance at the $5 \%$ level and *** indicates significance at the $1 \%$ level. Dummy variables for electricity supply regions, electricity/energy supplier before TBS, other payment types and purchasing from the incumbent supplier were also included as controls in the regressions but are not reported for brevity. By column, the number of the electricity supply region dummies (null region: London) significant at the 5\% level is: column 1-12, column 2-11, column 3-3, and column 4-2. By column, the number of the dummy variables for electricity/energy suppliers (null supplier: British Gas) significant at the $5 \%$ level is: column 1-11, column 2-9, column 3-7, and column 4-3. Details of the complete results are available on request.

Sample Selection: The regressions in columns 2-4 were all found to be subject to a significant sample selection effect compared to the 'All participants' sample. This sample selection effect was indicated by, and controlled for, including the relevant Inverse Mills Ratio (IMR) in each regression. In column 2 the IMR was negative and significant at the $1 \%$ level, while in columns 3 and 4 the IMR was positive and significant at the $1 \%$ level.

Null categories for reported dummy variables: 2 . No Exit Fee; 3. Energy bill not estimated by Which; 4. "Non-round" energy bill figure entered by participants; and 5. Shown one offer

Observations dropped by regressions: Column 1: 1 observation dropped for Utilita perfectly predicting non-switching. Column 2: No observations were recorded for Utilita; 16 observations were dropped for Green Energy UK and Spark Energy perfectly predicting non-switching. Column 3: No observations were recorded for Utilita or Spark Energy; 2 observations were dropped for Sainsbury's Energy perfectly predicting non-switching. Column 4: No observations were recorded for Utilita, Spark Energy or Sainsbury's Energy; 3 observations were dropped for Green Energy UK and Good Energy perfectly predicting non-switching; 1 observation was dropped for National Trust perfectly predicting switching. 


\section{APPENDIX 2: ONE VS TWO OFFERS}

In this appendix we present some additional analysis used to explore the finding that being shown two offers is associated with a lower probability of switching.

In table A2.1 the main demographic and socio-economic descriptive statistics are split by those who received one offer and those who received two offers. Table A2.1 reveals that the differences in respondent characteristics between the one and two offer groups are generally small in magnitude.

Table A2.1: Demographic and socio-economic characteristics of those receiving one and two offers

\begin{tabular}{lcc}
\hline Statistic & One Offer & Two Offers \\
\hline Age group containing median age ${ }^{1}$ & $55-64$ & $55-64$ \\
\% Male & 72.4 & 71.9 \\
\% Respondents with first degree or higher & 61.5 & 61.7 \\
\% Respondents who fully or partly own their home & 93.8 & 93.6 \\
\% Households containing at least one person who is & 54.2 & 54.4 \\
employed (part-time or full-time) & 7.9 & 7.6 \\
\% Respondents receiving a disability benefit & 8.4 & 8.5 \\
\% Respondents receiving an energy related benefit & $£ 30,000-34,999$ & $£ 35,000-39,999$ \\
$\quad$ (excluding Winter Fuel Payments) & $\mathbf{3 , 7 5 4}$ & $\mathbf{3 , 6 1 3}$ \\
Income category containing median income ${ }^{2}$ & \\
\hline Total Number of Observations & \\
1 Based on the 4,666 observations for which age information is available. \\
${ }^{2}$ Based on the 7,064 observations for which income information is available. \\
None of the percentages were significantly different at the 5\% level.
\end{tabular}

Table A2.2 shows that those receiving two offers had a higher median bill and were offered larger savings in both absolute and percentage terms.

Table A2.2: Financial information for those receiving one and two offers

\begin{tabular}{lcc}
\hline Statistic & One Offer & Two Offers \\
\hline Financial Factors & & \\
Median size of bill $(£)$ & 1131 & $1209^{*}$ \\
Median size of saving $(£)^{1}$ & 103.82 & $110.07^{*}$ \\
Median saving as percentage of existing bill ${ }^{1}$ & 9.8 & $10.2^{*}$ \\
\% Existing energy deal includes an exit fee & 16.2 & 16.7 \\
\hline Total Number of Observations & $\mathbf{3 , 7 5 4}$ & $\mathbf{3 , 6 1 3}$ \\
\hline * Indicates the median for the two offers group is different to the median for the one offer group \\
at the 5\% significance level. \\
${ }^{1}$ The median saving was calculated based only on participants who were offered a positive \\
saving as part of TBS.
\end{tabular}

Average marginal effects for separate one and two offer regressions are reported in Table A2.3 below. While most variables remain highly significant in both the one and two offer regressions, there are some notable exceptions. For example, Co-Op as a respondent's existing energy supplier loses statistical significance in the one offer model and is only significant at the $10 \%$ level in the two offer model. ${ }^{29}$

29. Due to the reduced sample sizes of the separate one and two offer regressions compared to the combined regression it is difficult to know if the loss of significance is due to a more accurate model of respondents' choice decisions from using two separate regressions rather than just a loss of statistical power. 
Using the two models in Table A2.3 it is possible to estimate the predicted probability of switching for those shown one offer and those shown two offers. The mean predicted probability of switching for those shown two offers is 12.4 percentage points lower than for those shown one offer (35.3\% vs 47.9\%). However, this does not control for the fact that those shown two offers have different characteristics from those shown one offer. This issue can be overcome by calculating the mean predicted probability of switching for all survey respondents using the one offer model and comparing this against the mean predicted probability of switching for all survey respondents using the two offer model. This latter approach still yields a lower average predicted probability of switching associated with two rather than one offer; however, the magnitude of the effect is reduced to only 2.8 percentage points $(39.6 \%$ vs $42.4 \%) .{ }^{30}$ While this result is interesting in the context of TBS, it is unclear how far it is generalizable.

Table A2.3: Selected average marginal effects on the probability of switching (separate 1 vs 2 offer regressions)

\begin{tabular}{|c|c|c|c|}
\hline Switching Factor & Variable & $\begin{array}{l}\text { Average Marginal } \\
\text { Effect-One Offer }\end{array}$ & $\begin{array}{l}\text { Average Marginal } \\
\text { Effect-Two Offers }\end{array}$ \\
\hline \multirow[t]{5}{*}{ Monetary Savings } & 1. Saving amount of the best offer ( $£ 10$ units) & $0.018 * * *$ & $0.015 * * *$ \\
\hline & 2. Has an Exit Fee & $-0.167 * * *$ & $-0.162 * * *$ \\
\hline & $\begin{array}{l}\text { 3. No other penalty/loss of benefits if switch } \\
\text { supplier }\end{array}$ & $0.061 * * *$ & 0.040 \\
\hline & $\begin{array}{l}\text { 4. Top } 3 \text { factor persuading to switch: Large } \\
\text { enough saving }\end{array}$ & $-0.032 * *$ & $-0.039 * *$ \\
\hline & $\begin{array}{l}\text { 5. Stated minimum required saving to switch } \\
\text { (Spring 2013, £1 units) }\end{array}$ & $-0.002 * * *$ & $-0.001 * * *$ \\
\hline \multirow[t]{6}{*}{ Non-Price Preferences } & $\begin{array}{l}\text { 6. Electricity/energy supplier before TBS: } \\
\text { Co-Operative Energy }\end{array}$ & 0.081 & 0.111 \\
\hline & 7. Prefers existing supplier re: tariff type & $-0.135^{* * *}$ & $-0.161 * * *$ \\
\hline & $\begin{array}{l}\text { 8. Prefers offered supplier on ethical/ } \\
\text { environmental grounds }\end{array}$ & $0.118 * * *$ & $0.100 * * *$ \\
\hline & 9. Prefers offered supplier re: tariff type & $0.217 * * *$ & $0.136^{* * *}$ \\
\hline & $\begin{array}{l}\text { 10. Prefers offered supplier re: payment } \\
\text { method }\end{array}$ & -0.015 & $0.096 * * *$ \\
\hline & 11.Prefers offered supplier for 'Other' reason & $0.170 * * *$ & $0.068 * *$ \\
\hline Uncertainty/ & 12. Confidence in accuracy of TBS saving ( 0 & $0.061 * *$ & -0.005 \\
\hline \multirow[t]{4}{*}{ Preparedness } & to 1$)$ & & \\
\hline & 13. Energy bill estimated by Which & $-0.084 * * *$ & $-0.064 * * *$ \\
\hline & 14. Respondent states bill as 'Round' amount & -0.037 & $-0.062 * *$ \\
\hline & $\begin{array}{l}\text { 15. Unsure if other penalty/loss of benefits if } \\
\text { switch supplier }\end{array}$ & -0.024 & $-0.094 * * *$ \\
\hline Concerns with & 16. Worried re: 'Other' issues & $-0.111 * * *$ & $-0.104 * * *$ \\
\hline \multirow[t]{3}{*}{ Switching Process } & 17. Additional help wanted: phone support & $-0.046^{* *}$ & $-0.052 * *$ \\
\hline & 18. Add'1 help wanted: simpler switching & $-0.106^{* * *}$ & $-0.099 * * *$ \\
\hline & 19. Additional help wanted: something else & $-0.075^{* * *}$ & $-0.061 * * *$ \\
\hline \multirow[t]{5}{*}{ Time Pressures } & 20. Worried switching time consuming & 0.005 & $0.085 * * *$ \\
\hline & $\begin{array}{l}\text { 21. TBS was a very busy period: Strongly } \\
\text { Agree }\end{array}$ & $-0.209 * * *$ & $-0.245^{* * *}$ \\
\hline & 22. TBS was a very busy period: Agree & $-0.094 * * *$ & $-0.128 * * *$ \\
\hline & 23. TBS was a very busy period: Disagree & $0.028 * *$ & $0.040^{* * *}$ \\
\hline & $\begin{array}{l}\text { 24. TBS was a very busy period: Strongly } \\
\text { Disagree }\end{array}$ & -0.022 & -0.009 \\
\hline
\end{tabular}

(continued)

30. Both of the reported differences in predicted switching probability are significant at the $1 \%$ level. The statistically significant drop in the predicted probability of switching when shown two offers is robust to removing variable 35 in Table A2.3 (the difference between offers) from the two-offer regression. 
Table A2.3: Selected average marginal effects on the probability of switching (separate 1 vs 2 offer regressions) (continued)

\begin{tabular}{|c|c|c|c|}
\hline Switching Factor & Variable & $\begin{array}{l}\text { Average Marginal } \\
\text { Effect-One Offer }\end{array}$ & $\begin{array}{l}\text { Average Marginal } \\
\text { Effect-Two Offers }\end{array}$ \\
\hline \multirow[t]{3}{*}{ TBS Specific Factors } & $\begin{array}{l}\text { 25. Top } 3 \text { factor persuading to switch: } \\
\text { Confidence in getting best possible deal }\end{array}$ & 0.010 & $0.039 * *$ \\
\hline & $\begin{array}{l}\text { 26. Top } 3 \text { factor persuading to switch: Ethical/ } \\
\text { environmental reasons }\end{array}$ & $0.035^{*}$ & 0.019 \\
\hline & $\begin{array}{l}\text { 27. Top } 3 \text { factor persuading to switch: Quick } \\
\text { and easy switching process }\end{array}$ & 0.025 & 0.020 \\
\hline \multirow{3}{*}{$\begin{array}{l}\text { Respondent } \\
\text { Characteristics }\end{array}$} & 28. Number of people in household: One & $0.044 * * *$ & 0.026 \\
\hline & $\begin{array}{l}\text { 29. Highest Educational Qualification: } \\
\text { Masters } / \mathrm{PhD}\end{array}$ & 0.015 & $0.036 * *$ \\
\hline & 30. Gender: Male & $0.029 * *$ & -0.012 \\
\hline \multirow[t]{2}{*}{ Other } & $\begin{array}{l}\text { 31. Saving of best offer less saving of the } \\
\text { Co-Op }\end{array}$ & & $-0.001 * * *$ \\
\hline & 32. IMR for survey response & -0.025 & 0.243 \\
\hline $\mathbf{N}$ & & 3,754 & 3,613 \\
\hline
\end{tabular}

Notes: * indicates significance at the $10 \%$ level, $* *$ indicates significance at the $5 \%$ level and $* * *$ indicates significance at the $1 \%$ level. The table focuses on statistically significant variables. A wide range of additional variables were included in the regression, but are not reported for brevity. These variables include: payment method before TBS, household tenure, employment status of household members, whether in receipt of a fuel related benefit and interactions with existing supplier triggered by TBS. In particular, dummy variables for electricity supply regions and median household income in a respondent's postcode area were included and generally found to be statistically insignificant. Additionally, dummies for extra options beyond those listed in the current table were included for: factors that would persuade a respondent to switch, preferences between previous and offered suppliers, worries about the switching process, additional help wanted, number of household members and highest educational qualification obtained. Details of the complete regression results are available on request.

Null categories for reported dummy variables: 2. No Exit Fee; 3. and 15. Has a penalty/loss of benefits if switch; 4. and 25. to 27 . Listed factor not in the top 3 factors that would persuade the respondent to switch in the future; 6 . Electricity/energy supplier before TBS - Not Co-operative Energy or EBICo; 7. to 11. Indifferent between existing and offered supplier on stated dimension; 13. and 14. Respondent used actual bill and stated 'Non-Round' amount; 16. and 20. Not worried about stated issue; 17. to 19 . The form of additional help stated was not required; 21 . to 24 . Neither agree nor disagree with the statement 'TBS was a very busy period'; 28.2 people in household; 29. Highest educational qualification - first degree or equivalent; 30. Female. 


\section{APPENDIX 3: SUPPORTING MATERIALS}

Table A3.1: Comparison of Analysed group with all survey respondents and with average UK household characteristics

\begin{tabular}{lccc}
\hline Characteristic & $\begin{array}{c}\text { 2013 Survey } \\
\text { Respondents Offered } \\
\text { Saving at TBS }\end{array}$ & $\begin{array}{c}\text { 2013 Survey } \\
\text { Respondents- } \\
\text { Filters Applied }\end{array}$ & $\begin{array}{c}\text { Equivalent } \\
\text { figure for GB }\end{array}$ \\
\hline Age group containing median age ${ }^{1}$ & $55-64$ & $55-64$ & $35-44$ \\
\% male & $70.6^{*}$ & $72.2^{*, \wedge}$ & 48.3 \\
\% with first degree or higher & $60.0^{*}$ & $61.6^{*}$, & 23.0 \\
\% who rent their home & $6.6^{*}$ & $6.2^{*}$ & 35.5 \\
\% of households receiving disability benefit & $7.5^{*}$ & $7.7^{*}$ & $9.8^{4}$ \\
Category containing median household income ${ }^{2}$ & $£ 30,000-34,999$ & $£ 35,000-39,999$ & $£ 35,000-39,999$ \\
\hline Total number of observations & $\mathbf{1 2 , 7 5 0}$ & $\mathbf{7 , 3 6 7}$ & - \\
\hline
\end{tabular}

Notes: The first column represents all those who responded to the survey (it was sent to half of all TBS participants) and who were offered a positive saving at TBS. The second column is a subset of the first column involving those respondents who were supplied by a single supplier before TBS, entered the direct debit auction and who stated saving money as one of the top three reasons for participating in TBS.

* Indicates the statistic is significantly different from the figure for GB as a whole at the $5 \%$ level.

$\wedge$ Indicates the statistic for analysed respondents is significantly different to the figure for all survey respondents at the $5 \%$ level.

${ }^{1}$ Age information was only available for 10,864 of the survey respondents and 4,666 of the filtered survey respondents.

${ }^{2}$ No specific question about income was asked in the survey. These figures are based on the median income of inhabitants of the six digit post code area where the respondent lived. Such income information was available for only 12,202 survey respondents (7,064 respondents among the filtered group).

${ }^{3}$ These statistics are based on tables available in Ofgem (2014).

${ }^{4}$ This is the percentage of respondents having responsibility for members of the immediate family with long-standing illness, physical or mental health problems or disability. 
Table A3.2: Average marginal effects for statistically significant variables predicting the selection from all TBS participants to filtered survey respondents

\begin{tabular}{lc}
\multicolumn{1}{c}{ Variables } & $\begin{array}{c}\text { Average Marginal } \\
\text { Effect }\end{array}$ \\
\hline 1. Saving amount of the best offer (£10 units) & $0.002^{* * *}$ \\
2. Energy expenditure before TBS & $-0.000^{* * *}$ \\
3. Energy bill estimated by Which & $0.026^{* * *}$ \\
4. Has an Exit Fee & $0.016^{* * *}$ \\
5. Doesn't know if has an Exit Fee & $-0.006^{* * *}$ \\
6. Before TBS received electricity and gas from a single supplier & $0.012^{* * *}$ \\
7. Before TBS with incumbent supplier(s) for electricity and/or gas & $-0.029^{* * *}$ \\
8. Before TBS received both gas and electricity from either British Gas or & $-0.006^{* * *}$ \\
the incumbent regional electricity supplier & \\
9. Bill before TBS paid by Cash & $-0.058^{* * *}$ \\
10. Bill before TBS paid by variable Direct Debit & $-0.015^{* * *}$ \\
11. Shown two offers & $0.007^{* * *}$ \\
12. Method/venue where participant joined TBS known & $0.006^{* * *}$ \\
13. Reminder email sent as part of TBS phase II & $-0.012^{* * *}$ \\
14. Reminder email sent as part of TBS phase III & $0.005^{* *}$ \\
15. Electricity supply region: Scottish Hydro & $0.011^{* *}$ \\
16. Electricity supply region: Seeboard & $-0.010^{* * *}$ \\
17. Electricity supply region: Southern Electric & $0.005^{*}$ \\
18. Electricity supply region: Yorkshire & $-0.007^{* *}$ \\
19. Electricity/energy supplier before TBS: npower & $-0.006^{* *}$ \\
20. Electricity/energy supplier before TBS: Good Energy & $-0.099^{* * *}$ \\
21. Electricity/energy supplier before TBS: Southern Electric & $-0.016^{* * *}$ \\
22. Electricity/energy supplier before TBS: Ecotricity & $-0.049^{* * *}$ \\
23. Electricity/energy supplier before TBS: EDF Energy & $-0.011^{* * *}$ \\
24. Electricity/energy supplier before TBS: The Utility Warehouse & $-0.034^{* * *}$ \\
25. Electricity/energy supplier before TBS: first:utility & $0.018^{* * *}$ \\
26. Electricity/energy supplier before TBS: OVO Energy & $0.009^{*}$ \\
27. Electricity/energy supplier before TBS: M\&S Energy & $-0.015^{* *}$ \\
28. Electricity/energy supplier before TBS: Co-Operative Energy & $0.025^{* * *}$ \\
\hline N & $\mathbf{1 3 9 , 5 9 4}$ \\
\hline
\end{tabular}

Notes: * indicates significance at the $10 \%$ level, ** indicates significance at the $5 \%$ level and *** indicates significance at the $1 \%$ level. Dummy variables for other electricity supply regions, other electricity/energy suppliers before TBS, other payment types were also included as controls in the regressions but are not reported. Details of the complete regression results are available on request. Null categories for reported dummy variables: 3. "Non-round" energy bill stated by respondent; 4. and 5. No Exit Fee; 6. Before TBS respondent received electricity and gas from separate suppliers or consumed only one fuel; 7. Receives gas or electricity from a non-incumbent supplier; 8 . Does not receive both electricity and gas from either British Gas or the incumbent supplier; 9. and 10. Bill before TBS paid by Fixed Direct Debit; 11. Shown one offer; 12. Method/venue where participant joined TBS not known; 13. Reminder email not sent as part of TBS phase II; 14. Reminder email not sent as part of TBS phase III; 15. to 18. Electricity supply region: London; 19. to 28. Electricity/ energy supplier: British Gas.

Observations dropped by regressions: 50 observations for Utilita, Spark Energy and Sainsbury's Energy were dropped for perfectly predicting non-inclusion in the final analysis. 
Table A3.3: Coefficients for potential instrumental variables from the regression estimating the minimum saving required to switch

\begin{tabular}{lc}
\hline \multicolumn{1}{c}{ Potential Instrumental Variable } & $\begin{array}{c}\text { Regression } \\
\text { Coefficient }\end{array}$ \\
\hline 1. Before TBS: On a Dual Fuel Tariff & $12.171^{* * *}$ \\
2. Respondent reminded of saving they were offered in TBS & $7.347^{* * *}$ \\
3. Respondent states saving needed using a slider covering the range $£ 0$ to & $29.134 * * *$ \\
$£ 1,000$ & $15.225^{* * *}$ \\
4. Respondent states saving needed using a slider covering the range $£ 0$ to $£ 500$ & 4.815 \\
5. Household member receives disability benefit & -2.833 \\
6. With the incumbent supplier(s) for electricity (and gas where applicable) & 1.354 \\
7. Both gas and electricity from one supplier: either British Gas or the incumbent \\
electricity supplier
\end{tabular}

\section{APPENDIX 4: ECONOMETRIC METHODOLOGY}

Our analysis models the probability of switching supplier based on an unobservable latent variable $\mathrm{y}_{\mathrm{i}}^{*}$ which measures utility consumers derive from switching, with $\boldsymbol{y}_{i}^{*}=\boldsymbol{x}_{\boldsymbol{i}}^{\prime} \boldsymbol{\beta}+\boldsymbol{\varepsilon}_{i}$ where $\mathbf{x}_{\mathbf{i}}$ is a set of observable exogenous variables and $\varepsilon_{\mathrm{i}}$ a Normally distributed error term. The econometric model used in the analysis is a Probit model where the dependent variable, $y_{i}$, takes a value of 1 when an individual switches energy supplier and a value of 0 when an individual does not do so. For each individual " $i$ " it is possible to model the probability, $p_{i}$, of a switch occurring as:

$$
y_{i}=\left\{\begin{array}{rrr}
1 & \text { with probability } & p_{i} \\
0 & \text { with probability } & 1-p_{i}
\end{array}\right\}
$$

We expect to observe $y_{i}=1$ if $y_{i}^{*}>0$. Formally, the probability of an individual switching, $p_{i}$, can be modelled as:

$$
p_{i}=\operatorname{Prob}\left(y_{i}=1 \mid \boldsymbol{x}_{\boldsymbol{i}}\right)=F\left(\boldsymbol{x}_{\boldsymbol{i}}^{\prime} \boldsymbol{\beta}\right)
$$

where $p_{i}$ is the probability that switching is observed given the values of the explanatory variables, $\boldsymbol{x}_{\boldsymbol{i}}$.

When modelling the decision to switch supplier we encountered two main modelling challenges: (i) sample selection, and (ii) endogeneity issues. In this technical appendix we discuss the 
methods used to address these issues, namely the Heckman 2-stage approach and the conditional maximum likelihood (instrumental variable approach). The main sources for the material discussed below are Cameron and Trivedi (2005) and Greene (2011).

\section{(i) Heckman 2-stage}

We acknowledge that the sample we used for the empirical analysis could be subject to sample selection issues and for this reason we modelled the self-selection mechanism as: $\mathrm{z}_{\mathrm{i}}^{*}=\mathrm{w}_{\mathrm{i}}^{\prime} \gamma$ $+\mathrm{u}_{\mathrm{i}}$, with $\mathrm{z}_{\mathrm{i}}=1$ if $\mathrm{z}_{\mathrm{i}}^{*}>0$ and 0 otherwise. Where $\mathrm{z}_{\mathrm{i}}^{*}$ represent a latent variable measuring the propensity to participate to our survey while $\mathrm{w}_{\mathrm{i}}$ represents a matrix of explanatory variables affecting the propensity to participate and $\gamma$ represents the vector of associated coefficients. $z_{\mathrm{i}}$ is a $0 / 1$ variable reflecting actual participation in the survey.

Based on this set up we can calculate the probability of taking part in the survey by first estimating by maximum likelihood a Probit model for the probability of participating (stage 1 of the Heckman 2-stage approach):

$$
p_{i}=\operatorname{Prob}\left(z_{i}=1 \mid \boldsymbol{w}_{\boldsymbol{i}}\right)=\boldsymbol{\Phi}\left(\boldsymbol{w}_{\boldsymbol{i}}^{\prime} \gamma\right)
$$

Where $\varphi$ is the Normal probability distribution function and $\Phi$ the cumulative distribution function.

From this equation we can construct the Inverse Mills Ratio (IMR) as:

$$
\widehat{\lambda}_{i}=\varphi\left(w_{i}^{\prime} \hat{\gamma}\right) / \Phi\left(w_{i}^{\prime} \hat{\gamma}\right)
$$

Stage 2 of the Heckman 2-stage approach involves including $\hat{\lambda}$ in equation (A.1) as an additional explanatory variable in $\mathbf{x}_{\mathbf{i}}$ to correct for the potential non-random nature of our sample, which includes only individuals who chose to participate in the survey.

\section{(ii) Conditional Maximum Likelihood Estimation}

Our Probit model for the probability of switching has been estimated using the conditional maximum likelihood estimation, an instrumental variable method, which deals with the potential endogeneity ${ }^{31}$ of the minimum required saving. This process involves the joint estimation of two equations, the first of which has the potential endogenous variable as a dependent variable. In order to account for the endogeneity bias, we chose a set of "instrumental variables" to be included as regressors in the second equation. The "instrumental variables" need to be correlated with the endogenous variable but independent of the decision to switch supplier. The main instrument we used in our analysis is the method we used for asking the respondents to report the minimum required saving to switch. ${ }^{32}$ While this variable is a highly significant predictor of the minimum required saving the random assignment of individuals between different methods means that it cannot be a predictor of switching, also recalling that our survey was conducted about one year after TBS, when the switching decision took place.

31. By endogeneity we mean that there could be common unobserved factors determining both the probability of switching and the minimum saving required to induce switching. Failing to properly account for this endogeneity could lead to biased and inconsistent estimates in the regressions.

32. Respondents were randomly allocated to six different treatments. Firstly, half the sample was reminded of the saving they were offered at TBS and half did not receive this reminder. Also, there were three variations in the way respondents were asked to record the saving they required: (i) on a grid with assigned values, (ii) using a slider with a maximum value of $£ 500$ and (iii) using a slider with a maximum value of $£ 1,000$. 
Suppose there are two endogenous variables, $y_{1 i}^{*}$ and $y_{2 i}$ (in other words, they are determined by the same underlying process). Assume that each endogenous variable can be represented by a linear equation. Also, assume each equation involves only two explanatory variables:

$$
\begin{aligned}
& y_{1 i}^{*}=\boldsymbol{x}_{1 i}^{\prime} \boldsymbol{\beta}+\alpha_{1} y_{2 i}+\varepsilon_{1 i} \\
& y_{2 i}=\boldsymbol{x}_{\boldsymbol{i}}^{\prime} \boldsymbol{\pi}+\varepsilon_{2 i}
\end{aligned}
$$

where $x_{1 i}$ and $x_{i}$ are exogenous variables, with $\mathrm{x}_{\mathrm{i}}$ representing the instrumental (exogenous) variable which influences $y_{2 i}$ but not $y_{1 i}$. $\beta$ and $\pi$ are vectors of coefficients associated with the explanatory variable whilst $\varepsilon_{1}$ and $\varepsilon_{2}$ are the error terms, assumed to be jointly Normally distributed. A Wald test for the independence of the error terms in the two equations, $\varepsilon_{1 \mathrm{i}}$ and $\varepsilon_{2 \mathrm{i}}$, led us to reject the null hypothesis of $y_{2}$ being exogenous. Equation (A.4) explaining $y_{1 i}$ is the structural equation of interest used to estimate a Probit model for the probability of switching, while equation (A.5) explains the endogenous regressor $y_{2 i}$. As in (i) we expect to observe $\mathrm{y}_{1 \mathrm{i}}=1$ when $\mathrm{y}_{1 \mathrm{i}}{ }^{*}>0$. We therefore express the probability of switching as:

$$
p_{1 i}=\operatorname{Prob}\left(y_{1 i}=1 \mid \boldsymbol{x}_{1 i}, \boldsymbol{y}_{2 i}\right)=F\left(\boldsymbol{x}_{1 i}^{\prime} \boldsymbol{\beta}+\alpha_{1} y_{2 i}\right)
$$

Based on the relationships described above we estimated the probability of switching supplier by conditional maximum likelihood, by maximising the following likelihood function:

$$
L\left(\alpha_{1}, \beta\right)=\sum_{1=1}^{N}\left\{y_{1 i} \ln F\left(\boldsymbol{x}_{1 i}^{\prime} \boldsymbol{\beta}+\alpha_{1} y_{2 i}\right)+\left(1-y_{i 1}\right) \ln \left(1-F\left(\boldsymbol{x}_{1 i}^{\prime} \boldsymbol{\beta}+\alpha_{1} y_{2 i}\right)\right)\right\}
$$

